\title{
UK Vietnamese Businesses: Cultural Influences and Intra-cultural Differences
}

\author{
Susan Bagwell, \\ Cities Institute, London Metropolitan University, Ladbroke House, 62-66 Highbury Grove, \\ London N5 2AD, England; \\ email: s.bagwell@londonmet.ac.uk
}

\begin{abstract}
Current UK policy views the encouragement of enterprise by Black and Minority Ethnic (BME) communities as a key strategy of both its social inclusion and competitiveness agenda. However the evidence suggests that the take-up of business support by these groups is very limited, and recent research has argued for the need for more culturally sensitive provision and a better understanding of the diverse needs of different BME groups. This paper reports on a study of first and second-generation Vietnamese businesses in London designed to explore traditional cultural influences on business practice. The results suggest that, as with many other ethnic groups, attitudes towards the family, trust, and language have a key impact on the start-up and operation of the businesses. However, this study suggests that the ways in which these three factors impinge on business practice vary between the older first generation (the original "boat people"), the UK educated second-generation, and younger more recent immigrants, and is also mediated by sectoral influences, the pressures of the market place and the degree of family involvement in the business. In particular $2^{\text {nd }}$ generation and recent immigrants were less likely to adopt traditional collectivist approaches to the running of their business compared with the first generation, but their business practice was still often influenced by strong family loyalties. The paper argues that theories of ethnic minority enterprise that advocate a mixed embeddedness approach need to incorporate an historical dimension. The findings emphasize the need for enterprise support policy to take account not only of inter-cultural differences, but also the intra-cultural differences that exist within different ethnic minority groups. The paper makes a number of suggestions as to how policy and practice should be adapted accordingly.
\end{abstract}

\section{Introduction}

This paper is concerned with the provision of a more culturally sensitive business support service to ethnic minority businesses in the United Kingdom. It reports on a study designed to provide mainstream business advisers with a better understanding of the Vietnamese business community in London. The study was a response to Business Link's (the main UK business support service) need to develop an engagement strategy with some of the newer and lessor known business communities such as the Vietnamese.

The need to develop a more effective engagement strategy with black and minority ethnic businesses (BMEBs) has been a key concern of UK policy for some time. There are a number of reasons for this. Firstly demographic projections suggest that ethnic minorities will form a growing proportion of the UK population. By 2009 they are projected to make up half the growth in the working-age population. (Cabinet Office Strategy Unit 2003). In areas such as Greater London the BME population is expected to increase to almost one-third of London's population by 2011 (LDA 2005). Secondly, ethnic minority groups as a whole are currently overrepresented in business compared with their white counterparts, and are expected to form an increasing proportion of the small business stock in the future (NatWest Bank quoted in Financial World 2003 page 36). On the one hand BMEBs are now recognised as making a significant contribution to the economy. In London the turnover of BMEBs has recently been estimated as £90billion compared to £800billion for all London businesses (London Annual Business Survey 2004). The UK government 's competitiveness agenda views the further development of these businesses as an important source of future wealth and employment. At the 
same time it is also acknowledged that certain ethnic minority groups (noteably Afro-Caribbean, Pakistani and Bangladeshi men) are under-represented in business and experience higher levels of unemployment than the UK norm. Thus the UK's social inclusion policy views enterprise as a key source of employment for these disadvantaged groups.

The provision of enterprise support in its various forms, is generally viewed, by policy makers at least, as an effective means of stimulating small business start-up, survival and growth, and increasing the take-up of external business advice is one of the key targets of the UK government's Small Business Service Action Plan (2004). However, whilst businesses in general tend to show a low propensity to make use of business support services (Barclays/NFEA 2002), black and minority ethnic businesses have been found to be even less likely to seek advice from public or quasi public agencies than their white counterparts (Ram et al 2002). The reasons for this have been identified as being due in part to the tendency for some BME groups, notably Asians, to rely instead on family and community networks, but have also been attributed to the lack of cultural awareness and sensitivity of mainstream business support agencies (Oc and Tiesdell, 1999; Ram and Smallbone, 2002) and the inappropriateness of their largely 'productorientated' approaches which fail to tailor support to address the specific needs of the entrepreneur (Deakins et al, 2003).

This failure by mainstream agencies to attract BME clients has led to the funding of a number of dedicated BME agencies, and the hiring of BME staff within mainstream agencies. Whilst these may find it easier to develop trust-based relationships, they may have more difficultly establishing their professional credibility (Ram and Smallbone, 2002). Thus some agencies have attempted to provide diversity training for mainstream advisors. For example, the Knowledge Centre on Black and Ethnic Minority Businesses was set up by Business Link for London to act as a central resource and knowledge base for information on BMEs, and to offer specialist advice and diversity training to mainstream advisers.

Alternative strategies have been based on the viewpoint that the underlying needs of businesses are mainly dependent on their size and sectoral characteristics, and have focused on targeting support on key sectors, such as clothing, retail and catering, where BMEs are heavily concentrated. Whilst this approach has met with some successes it has also been suggested that, "culture can, in certain circumstances, result in an additional dimension that may have implications for how the needs are effectively addressed. As a result, it is with respect to delivery methods that the needs of EMBs require special attention" (Ram and Smallbone, 2002, page 247). Thus current policy tends to advocate a focus on business type and sector rather than ethnicity but argues that the provision of enterprise support needs to be sensitive to different ethnic cultures (ODPM 2003).

An added dimension is the growth in the number of second and third generation ethnic minorities. This group, having been educated in the UK does not face the same cultural and linguistic barriers as their parents and there is some research to suggest that many are forsaking their parents business for a career in the professions or entering very different sectors to those of their parents. (Chan 1997, Pang 1999). This raises a question about whether or not an enterprise support policy should assume that they have been largely assimulated into the mainstream, or whether they still have cultural or other unique needs.

The aim of this paper is to address the above issues by exploring the complex way in which ethnic group culture interacts with sectoral and generational issues to influence business behaviour. It reports on the findings of a study of Vietnamese businesses in London that has explored the influence of traditional Vietnamese culture on business practice. This group is interesting, not only because it has not been the subject of any previous UK based research, but also because, although still relatively small in size, it is rapidly expanding and now making a significant contribution to the local economy in a number of inner city areas (Bagwell et al 2003). Also, although initially a refugee community, it is now made up of second generation and new migrant businesses. Thus by investigating how culture influences the entrepreneurial practice of 
these groups in different ways the paper seeks to demonstrate the importance of acknowledging intra-group differences and adapting policy and practice accordingly.

The paper deals in section 2 with a summary of relevant literature on this subject. Section 3 describes the methodology adopted by the study, and in section 4 the results are analysed. The paper concludes in section 5 with some suggestions for future enterprise support policy.

\section{Literature Review}

\subsection{Culture and Entrepreneurship}

Culture has been defined as, "the collective programming of the mind which distinguishes the members of one group or category of people from those of another" (Hofstede, 1991, page5). The core of culture is formed by values (Hofstede, 1991) and value systems are shaped by factors such as religion, proximity, history, and education (Harris, 1979; Rosen and Shenkar, 1985). Core cultural values are thought to be learned during childhood (Hofstede, 1980) and cultural studies research generally agrees that most of an individual's values are entrenched by their late-teens (Ralston, 1999a), but do evolve from generation to generation (Ajiferuke and Boddewyn, 1979).

Hofstede's research shows how national culture influences workplace values across a range of countries. His work has been used to show that certain national cultures, notably those that are more individualistic, tend to produce more business start-ups than others. However these crosscultural studies have been criticised for tending to use the term culture and nation interchangeably (Tan, 2002) and for ignoring the existence of different cultural groups within a country (Basru, 2002).

The relative influence of national as opposed to ethnic group culture is particularly pertinent to the study of immigrant and ethnic minority entrepreneurs. If cultural values are relatively static by the time adulthood is reached we would expect immigrant entrepreneurs to retain most of their traditional cultural values when they migrate. Their children however will also be influenced by the national culture of the country to which their family migrated and thus secondgeneration entrepreneurs may hold very different values to those of their parents. Thus as Hofstede (1991) notes "layers of culture" exist which might include the national level, regional or ethnic/religious/linguistic levels, gender, generational and social class levels.

Early theories of ethnic minority entrepreneurship, developed in the West suggested that cultural differences accounted for the differing start-up and success rates of different ethnic groups. Ethnic minority entrepreneurs were seen as possessing unique cultural factors or 'social capital' not generally available to the mainstream (Coleman, 1988). This included cheap family labour, access to trusted networks which facilitated trade and provided access to information, and pooled financial resources, which facilitated start-up (Light et al, 1993; Waldinger, 1995). The 'self-help' ethos of ethnic minorities accounted for their greater presence in business (Werbner, 1990) and the differences in start-up rates of different ethnic minority groups could be explained by their differing degrees of social capital which gave certain groups, notably Asians, a competitive advantage over others (Soar, 1991).

Particular cultural attributes have been used to explain the different performance of different ethnic minority groups. For example Islamic religious values, which prohibit the payment of interest on bank loans, have been found to inhibit the development of Pakistani businesses (Metcalf et al, 1996), whilst strong educational values are said to contribute to the greater success of Indian and East African Asians (Basru, 2002).

However critiques of the culturalist approaches argue that they often fail to take account of the wider environment (Ram and Jones, 1998), class differences (Mulholland, 1997), or sectoral influences (Ram et al, 2000). Recent theories have advocated a more interactive framework of mixed embededness in which the internal ethnic resources and cultural milieu of the ethnic entrepreneur interact with the external influences of the wider economic and institutional 
environment (Kloosterman, et al 1999). This suggests that ethnic minority entrepreneurship is influenced by the complex interplay of a range of factors including sector, locality, labour markets and institutional support. However whilst this mixed embeddeness approach has been widely embraced as offering a more comprehensive explanation than previous models, it has been criticised for assuming that traits are static and homogeneous (Chan, 1997), and for failing to explain the wide-ranging inter-ethnic variation in entrepreneurial concentration observed among immigrant groups around the world (Peters, 2002). Peters (2002) agues that the model needs to incorporate a historical perspective which acknowledges the development of entrepreneurship within a group over time. His analysis of data gathered on different groups of Dutch, Italian, Greek and Vietnamese entrepreneurs in Western Australia suggested that marked differences existed between first and second generation and second wave entrepreneurs in terms of their reasons for being self-employed and with respect to the resources they utlise to establish and operate their firms.

\subsection{Second Generation Ethnic Minority Businesses}

Research on generational influences on entrepreneurship is still in its infancy and in the UK has tended to focus on the South Asian and Chinese who are among the longest established BME communities. These studies suggest that the second generation are likely to have very different motivations and adopt different approaches to the management of their businesses than their parents. One reason given for this is the wider career options that tend to be available to the second-generation by virtue of their better education (Janjuha-Jivraj and Woods, 2002). A key finding is the particular desire of many second-generation ethnic minority groups to seek employment in the professions in preference to self-employment (Metcalf et al, 1996; Chan, 1997).

Those that do go into business have shown a greater tendency to set up in different sectors to those of their parents choosing the professions or emerging sectors such as IT (Pang 1999, Ram and Smallbone 2001). In the operation of their business second generation entrepreneurs have also been found to be more innovative, have staff involved in training, and be more open to using external sources of business support (Ram and Smallbone 2001). In addition they often have different perceptions regarding their ethnicity (Peters 2002). Peters' study suggested that for the first generation ethnicity was largely a source of ethnic group social cohesion, whilst the second generation saw their ethnicity as a resource, which could either be suppressed or exploited depending on the situation (Peters 2002). They also had the advantage of being able to exploit two cultural milieus for information, finance, labour and consumers.

In one of the few studies of smaller BME groups Masurel and Nijkamp (2004) identified differences in motivations for business start-up between first and second-generation Turkish business owners in the Netherlands. The first generation were more motivated by push factors, whilst pull factors were a key influence on the second generation. The generational differences were not as great as might have been expected, however, leading the researchers to suggest that this might be due in part to the possibility that Turkish culture may not have changed significantly in the last decades or because the first generation has adapted more quickly than expected to the new environment. Since the second generation showed more comparable motivation to native start-ups, it was argued that they could be partially integrated into mainstream business support programmes, but the first generation was very different and thus needed different forms of support. Masurel and Nijkamp suggested that tailor-made approaches for different groups of ethnic minority enterprises were needed.

Research with many second generation BMEs in the UK however, suggests that some groups do not necessarily want to be classified as BMEs, but prefer to be treated the same as others involved in similar activities (Ram and Smallbone, 2002). Others argue that they do not need

specialist language provision or BME advisors, but do want someone who understands their culture and what drives it (Dhaliwal, 2003). Clearly the issues are complex and vary within and 
across different groups. A much deeper understanding of the influence of culture and generation on entrepreneurship is therefore required if appropriate policy and enterprises support provision is to be developed.

\subsection{Changing Vietnamese Cultural Influences}

The literature on traditional Vietnamese culture focuses particularly on the strong influence of Confucian values and ideologies. Confucian philosophy provides a set of guidelines for social interaction, which are the underpinnings of social order in society. Confucianism urges individuals to adapt to the collectivity, control personal desires and emotions, restrain self-interest for the benefit of the group, avoid conflict, and maintain harmony (Kirkbridge and Tang, 1992, quoted in Yan and Sorenson, 2004). The interest of the family, group, or the whole society, should always precede the interests of the individual.

The most important social unit in society according to Confucian ideology is the family. Children are expected to respect and obey their parents and older relatives. Outside the family, a strict hierarchy of relationships operates based on status and age. Women are expected to show submission to their husbands and avoid direct conflict with men. The relationship between friends is the only equal one, and between friends trustworthiness is considered to be the most important virtue. Conformity to familial and social norms, and 'face' or an individual's public image is very important (Smith and Pham, 1996).

Confucianism teaches that social and economic activities are not based on competition, but on the collectivist principles of cooperation, coexistence, and mutual support. (Yan and Sorenson, 2004). Thus collectivist values see the individual as part of a social system with external concerns, obligations and duties.

The pervading influence of these traditional collectivist values amongst the overseas Vietnamese has been noted in studies of the Vietnamese community in America. Kibria (1994) found that the ideology of family collectivism had an important influence on the economic dynamics of the Vietnamese refugee households she studied in Philadelphia. This encouraged a collective, cooperative approach towards resources among household members by stressing the unity of family interests. Family households would determine and enforce collective goals and values.

There is some evidence to suggest that these traditional values may be changing however, at least in the younger generation. Ralston et al (1999a) argue that there will be potential changes in management values across generations, particularly where there have been major changes in the society. In his study of Chinese Managers in mainland China he found that the generation in which one grows up appears to be crucial to understanding the values of Chinese Managers. The younger generation are more likely to act independently and take risks in the pursuit of profit. Their values were clearly more individualistic, less collectivistic and less committed to Confucian philosophy than their previous generation counterparts.

Vietnam has undergone similar changes, albeit around 10 years later than China. Since the introduction of Doi Moi or market liberalisation in 1986 there has been more support for private enterprise and people are freer to travel and trade with the West. One might therefore assume that the value systems of the new generation of Vietnamese business managers might be becoming more individualistic. However research into the work values of north and south Vietnamese managers (Ralston et al, 1999b) suggests that whilst they may be adopting more individualist values they are not necessarily forsaking their collectivistic, Confucian roots.

Amongst the Vietnamese community in the West, Kibria (1994) noted that migration created conditions that undermined traditional values. In particular the traditional economic power of men in the community had declined as a result of their being periodically unemployed and women contributing the major share of the household income. This economic power shift challenged the traditional authority of men. Thus it would appear that traditional Vietnamese cultural values are changing due to the influence of economic pressures and host group culture. 


\subsection{Conclusions from the Literature}

The above analysis of the literature suggests that if cultural values are largely set by adolescence then one might assume that:

- the business practice of the older generation of Vietnamese businesses will be more influenced by traditional collectivist Confucian principles of commitment to community and family with hierachical relationships within the business based on age, status and male leadership.

- The second generation on the other hand have grown up in the more individualist society of the UK and one would expect their business practice to be influenced by more Westernised values in which individual desires tend to be more important than family or community.

- New migrants from Vietnam will have been influenced by the major changes which have taken place in the country since 1986 and are likely to demonstrate more individualist approaches to the operation of their businesses than the earlier older generation of refugees, but perhaps less than the second generation who have grown up in the UK Incorporating the above in a mixed embededness approach it is suggested that market opportunities, and the structural and legislative environment may mediate how these cultural influences translate into the actual strategies and behaviours adopted for running the business.

\section{Methodology}

The focus of this study was the Vietnamese business community in London. This group is to some extent illustrative of a number of the newer and smaller BME groups in the capital, although clearly it has its own distinct characteristics, and it is important to caution against generalising from this one fairly small study to other groups or the BME population as a whole.

The Vietnamese have been arriving in the UK since the fall of Saigon in 1975. These initial refugees or "boat people" were taken in under a planned resettlement programme. Initial government strategy was to distribute them across the country, but most later migrated to urban areas where there were better work opportunities and fellow community members. Most came from rural areas or small towns in North Vietnam and had limited educational qualifications, relevant work experience and skills transferable to the UK economy (Lam and Martin, 1997). This contrasts sharply with the Vietnamese community in the US, Canada and Australia who tended to originate from the more commercially orientated South Vietnam. A large number of the Vietnamese refugees sent to the UK spent time in refugee camps in Hong Kong before being accepted into the UK. This first wave were followed over the next 10-15 years by those allowed in as 'family reunion' cases.

Research on this community in the UK has focused to date on the problems they faced at the time of arrival and their general adaptation to life in UK (Duke and Marshall, 1997; Lam and Martin, 1997). A Home Office Study (Duke and Marshall, 1997) noted that in addition to the handicaps of language and interruption to education, the Vietnamese arrived in the UK during a period of high unemployment and recession. The study found a heavy reliance ( $45 \%$ of the sample) on informal contacts for finding employment and detected a trend towards selfemployment over time.

Developing a sample for a study such as the one reported here presents a number of challenges. The lack of available data on BMEs has been identified as a major issue by a number of studies. Deakinss et al, (2003 page 857) noted that, " there is still a widespread lack of robust intelligence on the characteristics and needs of EMBs in most agency databases." This is a particularly acute issue with smaller ethnic groups such as the Vietnamese. Most labour market and business surveys tend to classify the Vietnamese along with several other groups as 'Other Ethnic' (Labour Force Survey) or 'Other Asian' (London Employers Survey). The 2001 Census 
data records 2,053 self-employed people (17\% of the economically active) born in Vietnam living in UK, of which 800 are based in the greater London area ${ }^{1}$, but this of course does not include those born in London or elsewhere. To overcome the above difficulties and develop a database from which the research sample could be chosen a mapping exercise was undertaken as a prelude to the current study. This identified 284 Vietnamese businesses in Greater London, but key informant interviews suggested that the informal economy might account for a further 300-400 (Bagwell et al, 2003). In common with many other BME groups, Vietnamese businesses were concentrated in a few key sectors; restaurants, nail shops and mini-markets, or were providing specialist services, such as hairdressing or car maintenance within the ethnic enclave.

The fieldwork for this study included interviews with key actors from three Vietnamese community organisations and two focus groups, designed to identify key cultural issues, and 30 in-depth face-to-face interviews with owner managers.

Focus groups are useful for illiciting group norms and values, and wider structural issues affecting the businesses generally. They also "offer the possibility of a shift in the balance of power from the researchers to the business owners, which may benefit knowledge generation." (Blackburn and Stokes, 2001, page 44). This study used them to identify key issues, values and cultural norms, and to identify general issues affecting the different business sectors represented such as the marketplace and sources of support. Seven businesses participated in the first focus group held in English and a further five in a second group, which was conducted in Vietnamese.

The earlier mapping study (Bagwell et al, 2003) provided the population from which the businesses for the focus group discussions and individual interviews were selected. The sample was designed to be broadly representative of the range of business sectors and geographical distribution of the businesses in London, thereby enabling sectoral and locational influences on business practice to be taken into account. An attempt was also made to select equal numbers of male and female participants, and first and second-generation business owner managers. During the course of the study it was found that as well as the children of the original refugees, who had grown up in the UK, there was another similar aged group who had grown up in Vietnam or the refugee camps in Hong Kong, and then come to the UK more recently as an adult. This group was identified as the 'new arrivals'.

Previous research has noted the difficulties of interviewing ethnic minority enterprises. They often lack confidence in this type of research and there is also a fear that the provision of information on what are sometimes informal activities is not in the interest of the ethnic entrepreneur (Masurel and Nijkamp, 2004). In the case of refugees who have fled harsh government regimes in their country of origin there is also a natural suspicion of any activity that might be associated with officialdom. This study sought to overcome these barriers by hiring two Vietnamese-speaking research assistants to help with the recruitment of business participants. This also enabled us to offer the option of conducting interviews in Vietnamese. They and their contacts in the community provided vital access to the businesses, which would have otherwise been difficult to secure. The limitations of this approach were that the research was dependent on their networks and ability to encourage the participation of the businesses. This may have skewed the sample in favour of particular types of entrepreneur with whom it was easier to establish links. An attempt was made to overcome this by negotiating direct access to some of the businesses. In addition, towards the end of the study a Vietnamese speaking business advisor was appointed to one of the local enterprise agencies and she was able to provide a further route into the community and act as a vital 'sounding board' for the conclusions reached by the research.

The interviews and focus group discussions concentrated on the key stages of business development: start-up, operation of the business, and future plans and aspirations. A semistructured checklist was used to ensure that basic data was collected on the number of employees,

\footnotetext{
${ }^{1}$ Source: 2001 Census Commissioned Table. Crown copyright. 2003. Crown copyright material is reproduced with the permission of the Controller of HMSO
} 
age of business, education of owner; languages used, and markets in which the business operated. As far as possible, however, the owner was encouraged to tell his or her own 'story' about how s/he arrived in the UK, set up a business, and how the business was run. Storytelling is considered less likely to distort the interview process and can provide a "colourful understanding of how individual entrepreneurs are motivated and how they learn and gain experience" (Johanansson, 2004, page 285).

The two focus groups and the majority of the interviews were taped and transcribed yielding 28 useable transcripts of business interviews plus the two focus group discussions. These were analysed using NVivo software and emergent themes identified.

\section{Empirical Findings}

\subsection{The sample}

The businesses could be broadly divided into three different groups based on their history of migration:

- The first generation: who are defined for the purposes of this study as those who had left Vietnam as an adult (aged 15 years or over) and had been in the UK for 10 or more years. They had mostly arrived as refugees fleeing the communist regime in Vietnam in the late 70 s and 80 s

- The second generation: defined as those who left Vietnam as a child (aged 15 years or under), have been in the UK for 10 or more years and are the children of refugees who arrived in the late 1970s and 1980s.

- New arrivals: defined as those who had arrived in the UK during the last 10 years. This group had generally come to join family and friends in the UK and could be better described as economic migrants.

The main characteristics of these three groups and their businesses are summarised in Table 1 below. The sample included 11 restaurants/takeaways, 7 nail shops, one nail shop supplier, 2 mini-markets, and 7 other businesses including an architect's practice, clothing manufacturer, garage, hairdresser, herbal medicine shop, travel agent and video store. Whilst the sample is too small to allow generalisations about the community as a whole to be made, our general impression, which was reinforced by discussions with key informants, is that it offers a fairly typical picture of Vietnamese entrepreneurship in London. 
Table 1. Key characteristics of businesses and their owners

\begin{tabular}{|c|c|c|c|}
\hline Business owners characteristics & $\begin{array}{l}\text { First } \\
\text { generation } \\
\mathrm{n}=14\end{array}$ & $\begin{array}{l}\text { Second } \\
\text { generation } \\
n=9\end{array}$ & $\begin{array}{l}\text { New arrivals } \\
n=5\end{array}$ \\
\hline Average age on leaving Vietnam & 20 & 9 & 18 \\
\hline Average length of stay in UK & 19 & 22 & 7 \\
\hline \multicolumn{4}{|l|}{ Highest level of formal education } \\
\hline University & 2 & 6 & 1 \\
\hline Technical College & 2 & 1 & 1 \\
\hline Secondary School & 8 & 1 & 3 \\
\hline Primary/Junior School & 2 & 1 & \\
\hline \multicolumn{4}{|l|}{ Gender of Owner } \\
\hline Male & 9 & 2 & 1 \\
\hline Female & 5 & 7 & 4 \\
\hline \multicolumn{4}{|l|}{ Business Sector } \\
\hline Restaurant/Takeaway & 7 & $4^{*}$ & \\
\hline Nailshop/Nail supplier & 2 & 3 & 3 \\
\hline Mini-market & 1 & & 1 \\
\hline Other & 4 & 2 & 1 \\
\hline Average age of business & 4.5 years & 3.8 years** & 2.4 years \\
\hline No. with family working in business & 5 & 7 & 3 \\
\hline \multicolumn{4}{|c|}{$\begin{array}{l}\text { * } 2 \text { were jointly owned and established with older generation parents. } \\
\text { ** Average age of second-generation businesses reduces to } 2.8 \text { years if these two jointly } \\
\text { owned businesses are removed. }\end{array}$} \\
\hline
\end{tabular}

Two key points about the above data emerge. Firstly the second-generation UK educated group tended to be considerably better educated than both the first generation and the "new arrivals', reflecting the strong cultural value placed on education as a means of self-improvement. Secondly, most of the businesses were operating in ethnic niche markets providing specialist services to the local Vietnamese community (travel agents, hairdressers, video store, garage, mini-markets), or could be described as middlemen minorities (Ward, 1984) offering specialist ethnic services (restaurants/takeaways, nail shops) across a wider geographical area to the majority community. Only one real case of economic assimilation was identified; the secondgeneration architect's practice. This appeared to be the case across all three groups suggesting that the younger generation has yet to 'break-out' of the ethnic niche market.

\subsection{Business start-up}

A complex mix of motivations for start-up was identified. Discussions in the focus groups suggested that status was very important to the Vietnamese and that this lead to a cultural tendency to aspire to being one's own boss.

"A lot of it's about face - what people think of you. They want to be respectable" (second-generation business).

However interviews with the first generation suggested that the need to provide an income and employment for the family had been their key concern. A mixture of push and pull factors had been critical to business start up. The demise of the clothing sector in the mid 1990s, (a source of early employment for many first generation Vietnamese), had been a major push factor, 
whilst the cultural values of thrift, hard work, and strong family ties provided the necessary resources for start-up. Many had also by then acquired skills and savings, and had UK educated children who were now old enough to assist with the business, particularly in dealing with the paperwork involved.

Within the second-generation pull factors were more prominent, however the nature of these depended largely on the education of the owner manager. The nail shop owners, being less well educated tended to see the business as offering better economic prospects than alternative sources of employment. Their choice of business was dependent on access to family resources and contacts already working in the sector. The other business owners in this group all had university degrees and were more likely to have entered self-employment as a lifestyle choice. Two found it more compatible with looking after their young children and/or had set up businesses primarily as a means of helping provide employment for other members of their family. One of these, who had a masters degree, had left a well-paid job in the city to set up a café to give her parents, "something to do".

The 'new arrivals' in contrast tended to be more motivated by the economic potential of the business.

"As soon as I have enough money I will close the shop" ('newly arrived' mini-market owner).

Particularly apparent across all three groups was the key role played by local and global family networks in providing business ideas, and advice and training in setting up the business. The sample provided evidence of skills being learnt from the Vietnamese community in Europe and America. Nail shop owners in particular had frequently travelled to America to learn the trade from relatives running businesses there.

In common with many other BME groups the Vietnamese community, across all generations, tended to rely on informal finance from family and friends for start-up. The first generation businesses who had secured bank loans tended to be the more established businesses that had sought external financing for their second or third enterprise. Second generation businesses were more likely to have produced business plans and secured bank-loans for their first business, possibly reflecting weaker access to traditional sources of community support, a greater desire for independence and/or their better language skills and greater understanding of UK systems for business and finance. The 'new arrivals' not surprisingly, having no track record or assets in the UK, were totally dependent on family and friends or their own resources to finance start-up.

Thus for the first generation the motivation for entrepreneurship was based largely on the need for economic survival, whilst for the new arrivals economic advancement was the key factor. In contrast the second generation showed similar motivations to the wider population and an increasing tendency for business start-up to be influenced by their educational background and to be motivated by economic factors or lifestyle choices. Similarly the research detected a decreasing reliance on family and friends between the first and the second generation suggesting that traditional values and attitudes in which the family is seen as a collective economic unit were changing.

\subsection{The role of the family in the operation of the business}

The family played a key role in the operation of most of the businesses, as managers, employers and employees. The Vietnamese are not unique in this respect. Baines and Wheelcock (1998 page 582) note that "recent surveys have indicated that participation in small firms by owners' families is the norm rather than the exception in the UK". What was of interest however in this study, was the difference between the three groups in the extent to which they adopted a collective approach to the management of the business.

Within the first generation there was a greater tendency for the family to act as a collective unit in which members of the family shared ownership and responsibility for the running of the businesses. The following comment illustrates this more traditional collectivist approach. 
"In my family we have 7 brothers and sisters. ... Not really working for me, they are partners they are all family. It's not really a single man business" (first generation nail shop supplier). Comments from the 'newly arrived' generation suggested that the management of their business was less collectivist in nature, but that they still had a duty to support and provide employment for the family.

"All family members, cousins, nieces, nephews. .. I want to offer the opportunities to members of the family first. If there is still vacancies I would offer it to other people. ..There is an obligation to do it. I have a responsibility to find them work" ('newly arrived' male nail shop owner).

The tendency to employ family members in the business was equally strong across all generations, but appeared to be more influenced by the sector and size of the business and availability of family members needing work, rather than the age or generation of the owner. However the better educated and more business orientated second generation were more vocal about the problems involved in managing a family business. They felt that the collective decision making process common in the family business inhibited business development.

"When you have a family everyone wants to chip in and help make decisions. .. Everyone has opinions about how it should be done, even they may be outsiders and just come in to help you, they still have opinions, because they think they are family members and they think they can contribute" (second-generation restaurant owner).

The problems of working with older, especially male family members who according to traditional Vietnamese culture should be treated with respect caused particular problems with female second generation owner managers.

"If you hire a family member, there's this respect thing. I'm much younger than people who come in to help, parents and family. You can't instruct them in the same way as you could if they were younger. They expect you to show them some respect still" (second-generation female restaurant owner).

These findings suggest that both the second generation and the 'new arrivals' tended to have more individualistic values than those of the first generation. However the second generation felt more compromised by the need to comply with the social norms of their community than the 'new arrivals' did. The latter accepted their family obligations without question but were also more focused on the immediate economic returns of the business and did not suggest that the two were incompatible.

Interestingly, within each of the groups studied there were one or two businesses that did not adhere to this pattern. These businesses were run by well-educated, exceptionally independent, individuals, who were not constrained by family loyalties. They appeared to be more innovative and more successful at 'breaking-out' of traditional ethnic niche markets. For example the first generation travel agent interviewed had been educated in France before setting up his business, only two of his eight staff were Vietnamese, none were family members and his customers were not restricted to the Vietnamese community. Similarly the owner of a Japanese restaurant, had learnt to cook Japanese food from relatives in Germany and the US, and had received business advice from a well-educated relative in London, before starting his business. But he was single, his parents had stayed in Vietnam, and he was under no obligation to support other family members in the UK. These findings support those of Flap et al, (2000) who found that Turkish entrepreneurs in the Netherlands who came and stayed on their own developed more successful ventures than those with large extended families whom might initially support them, but later often expected their investment in the business to be reciprocated.

\subsection{The changing role of women}

Unlike other Asian groups where the number of male owners far outweighs female (Metcalf et al, 1996) we found a large number of women in business, particularly amongst the younger generations suggesting that the patriarchal nature of traditional Vietnamese society was changing. 
The recent war-torn history of Vietnam in which the men were often away fighting may be one contributory factor, and the economic necessity of women's work in the West is undoubtedly another. The key role played by women in small businesses generally and in ethnic minority businesses in particular, has been well documented by other researchers (Baines and Wheelock, 1998; Dhaliwal, 1998; Ram and Jones, 1998 ). In our sample the spouses of first generation owner-mangers usually played a key role in the business even if their husband was officially the "boss". As the Director of one of the community organisations explained, "The role of the wife may be in the background, the husband is in front but the decisions are made by the wife".

However many of the first generation women were beginning to resent their traditional role with respect to men. One female restaurant owner was angry that she was expected to respect the authority of her brother who had arrived more recently and had less business experience than her.

Second generation women were more likely to be business owners in their own right or play a more prominent role in the management of the family business, but still felt obliged to allow male members of the family working in the business to be seen in the public's eyes as the owner, as the following comment illustrates.

"My dad's just hanging around really. The customers think he's the boss, but he's just hanging around (second-generation restaurant owner)"

Thus traditional attitudes regarding the role of women were clearly changing across all generations, although this was not always publicly acknowledged. Second generation owners in particular appeared to be involved in negotiating a delicate balance between trying to manage the business effectively and needing to be seen by the co-ethnic community as adhering to traditional cultural norms. This suggested that economic pressures and host group cultures can have an impact on traditional cultural values and that cultural values are not so static as some would suggest.

\subsection{Religion and language}

Other studies (Metcalf et al, 96; Basru, 2002) have citied the importance of religious values to the operation of certain BME businesses. This did not appear to be the case with Vietnamese businesses. Whilst nearly all of those interviewed claimed to be either Catholic or Buddhist, and many had social networks based on the church or the temple and a shrine on the business premises, none felt their religion had any influence on how they ran their business.

The language skills of the owner manager, however, had a key impact on the business, frequently influencing the sectors of operation, the markets they operated in, the hiring of staff, and the ability to run the business effectively.

Amongst the older generation, language barriers and the difficulties this caused for dealing with regulatory requirements was the most frequently mentioned issue. After 15-20 years in the UK many still saw their poor English skills as a barrier and were heavily dependent on their children for helping them deal with the paperwork involved in running the business.

These language barriers had provided opportunities for others to offer specific services within the local ethnic economy. As one respondent a pointed out,

"... the Vietnamese customers can speak Vietnamese to describe damages of the car, it is more difficult to do that in English garages" (first generation garage owner).

Second generation business owners, having been educated in the UK, often found it easier to communicate in English than in Vietnamese. Interestingly many reported that they needed to use and in some cases re-learn Vietnamese in order to communicate with customers and employees.

"English is my main language. With my sisters, we speak English we always have done. We only speak Vietnamese to our parents. But to talk to staff, you have to talk in Vietnamese" (second generation restaurant).

The demands of the business were clearly motivating them to preserve a unique cultural asset. 
Thus for the first generation and some of the 'new arrivals' language could be a barrier or a useful business commodity. Whilst for the second generation it was seen as necessary for the effective operation of the business.

\subsection{Relationships with staff and the co-ethnic community}

Most businesses hired staff from the co-ethnic community if family members were not available. However contrary to the findings of other studies (Ram, 1999) in which those working in the business often referred to the benefit of having staff from same culture as they had a 'cultural understanding,' were 'on the same wavelength', shared similar moral values and could be trusted, the Vietnamese businesses were often highly critical of co-ethnic staff.

The first generation clearly felt that the traditional Vietnamese practice of showing respect for ones elders and superiors was breaking down amongst their younger employees. Restaurant owners feared that chefs had too much power, and nail shop owners complained that staff were unreliable and would quit without giving notice. At the same time traditional cultural norms dictated that they support their co-ethnic staff.

"We dare not put business operation in front of individual relationship. I have to confirm this is the serious trouble to old generation and seems to be less to younger one" (first generation focus group business).

The 'newly arrived' businesses did not seem to share these problems, possibly because they were smaller and thus better able to rely on family members to staff the business. But their comments suggested that their attitudes were still influenced by traditional community loyalties.

"...the main thing is I want to help some Vietnamese because for some people it's hard to find a job because of the language ('new arrival' nail shop).

In contrast the second generation were more likely to cite business needs as the main reason for employing co-ethnic staff. For example, one restaurant owner spoke of the need to hire Vietnamese staff for the sake of authenticity and because kitchen staff only spoke Vietnamese. They resented the traditional cultural tendency to expect reciprocal favours.

"With the Vietnamese, to get help you've got to give something - like give and take." and

"When they buy something they always ask for a reduction and it makes me feel really awkward" (second-generation video shop).

Thus the first generation were still trying to operate their business according to traditional practices based on reciprocity and respect for elders, but clearly these values were no longer respected by many of the wider community and the second generation businesses. For the latter the needs of the business were more important than any sense of commitment towards the wider community. The highly competitive marketplace increased this lack of community cohesion.

\subsection{Trust and community networks}

Trust emerged as a particularly important aspect of Vietnamese business life. Businesses of all ages and backgrounds mentioned the importance of building trust with suppliers, with partners and with customers. The first generation businesses had traditionally relied on trust rather than formal agreements for doing business and this practice still continued, although to a lesser extent amongst second-generation businesses,

"If you have a good relationship with someone then everything would be very easy.

Everything goes on trust. In Europe, everything has to be legal. Sometimes, we don't go

through a legal procedure, we just take it on trust" ( $2^{\text {nd }}$ generation nail shop).

But, whilst the wider community might be used for general business advice, most only trusted family and friends inside the business. The general lack of trust of anyone outside the close network of family and friends frequently inhibited the development of the business. There was a real concern that outsiders would steal vital trade secrets as the following quotes illustrate, 
"If I hire some people, they will know where my supplies come from in England, so they will buy direct from them and undercut my price" (first generation nail shop supplier).

"We don't trust anybody outside the family. We've got another restaurant in Hackney. If there wasn't a member of the family running it, we would rather rent it out and have nothing to do with it, just collect the rent" (son of first generation restaurant owner).

As research with other ethnic groups has found (Fadahunsi, 2000; Ram and Smallborne, 2003), the Vietnamese tend to rely on their own social and trusted community networks for business advice in preference to mainstream business advice agencies. One 'new arrival' nail shop owner said she preferred, "Advisors from real life. I don't trust agencies". According to the Vietnamese business advisor the businesses were also suspicious of any service which was offered by government agencies and/or which was free.

The second generation, whilst showing no greater tendency to use business advice, did show a greater propensity to make use of other sources of information. For example two of the nail shop owners mentioned attending trade shows and getting supplies and ideas from magazines or the internet. Several mentioned English friends. Thus by virtue of their UK education and proficiency in English they tended to have access to a wider range of networks than either the first generation or the 'new arrivals.' Despite this, their sense of obligation towards their family, often coupled with their need for family support with the business, meant that they were still strongly embedded in their family and community networks. The long hours worked, often 10-12 hours a day 7 days a week, meant that their was also little time for developing other contacts outside their existing family and social networks.

The lack of trust within the community may also account for the fact that the Vietnamese did not appear to have any business associations or be organised in any way. The recent political history of Vietnam, in which communities were divided, and where under communist rule enterprise was not encouraged, has possibly contributed to this lack of business connectivity.

Whatever the reasons, competition was cited as a major problem across the business community. The low entry threshold requirements of most of the sectors and the competitive markets in which most of the businesses operated increased their vulnerability. The increasing number of informal businesses, particularly in the nail-care sector, who would undercut the prices of licensed nail shops, created particular tensions within the community. Thus traditional practices of supporting one's community were undermined in the fight for survival. For many, undercutting each other had become the norm, and as one business owner put it, "We like competition. It's a cultural trait" (first generation nail shop supplier).

\section{Implications for Policy and Practice}

The above results suggest that traditional cultural values are by and large still held by the Vietnamese and do have an impact on business practice. The influence of traditional collectivist values towards the family, language and attitudes towards trust were found to be of particular importance to the businesses in our sample. As was expected the first generation owner managers were more likely to adopt traditional collectivist approaches towards the management of their business than either the second generation or the new arrivals. The exposure to more commercially orientated Western values in the UK and more recently in Vietnam had led both the second generation and the new arrivals to develop more individualist values, but despite this they still held a strong sense of loyalty towards the family.

However the extent to which cultural values influence the running of the business is also dependent on a range of other factors such as the business sector, the degree of family involvement in the business and the pressures of the market place. In particular collectivist value systems had a stronger impact on family businesses than non-family businesses and this was true across the three groups. As our results show the second generation may have more individualist views regarding to their business, but these can be constrained, particularly within a family 
business, by traditional loyalties towards the family and the need to conform to co-ethnic group norms. Equally the changing role of women and the weakened ties and commitment towards the community as a whole suggests that traditional values can be set aside if economic necessity dictates. Thus traditional cultural values can influence business practice, but adapt across generations and in response to economic pressures.

In highlighting the way in which economic pressures and structural changes interact with ethnic group culture this study adds further support to the theory of mixed embededness. However the results suggest, as Peters (2002) has argued, that the mixed embededness approach also needs to incorporate a historical perspective. Ethnic group cultures and the economic climate and opportunity structure change over time in both country of origin and country of migration resulting in significant differences in the values, motivations and business styles of different waves of immigrant entrepreneurs. This is likely to be particularly important where rapid and significant changes have occurred in the country of origin as has happened in Vietnam.

These finding have a number of implications for the delivery of business support to groups such as the Vietnamese. Firstly, an engagement strategy with BMEB and refugee businesses in particular needs to incorporate an understanding of a group's history of migration. Secondly, as other studies have noted an engagement strategy needs to be based on building trust and credibility with the business community. This is likely to be a particular challenge with the first generation and new arrivals because of on-going language barriers, their general mistrust of bureaucracy and outsiders, and the informal nature of many of the businesses, particularly those run by new-arrivals. This further emphasises the necessity, as identified by previous studies (Deakins et al, 2003; Ram and Carter, 2003) of employing or working through trusted intermediaries. Merely translating information into ethnic languages will not suffice, particularly in communities such as the Vietnamese that have a greater tradition of oral than written communication. With these groups the delivery of business support by co-ethnic business advisors who are known and trusted within the community is needed.

Thirdly, in the case of the UK educated second generation, their needs for support are more similar to those of the wider UK population, and it could be argued that they should be catered for within mainstream provision. However mainstream business advisors would benefit from an understanding of their cultural background, and the extent to which cultural obligations towards the family in particular, may influence business decisions. Whilst innovation and break-out need to be encouraged it is also important that support agencies acknowledge that some entrepreneurs choose to set up businesses in traditional sectors because these are perceived as offering the best source of employment for family members for whom they are responsible. The research has shown that this may be the case even with the better educated second generation who have the skills and aspirations to enter other areas. Thus as Saffru, (2003) has noted, support programmes designed to assist businesses run by more collectively oriented cultures should take account of the needs of the owner to balance the sometimes conflicting demands of community/family and business. Indeed it could be argued, that given the widespread involvement of the family in most businesses, not just BMEBs, that a more family embedded approach to the provision of business advice is needed throughout the enterprises support sector. As Aldrich and Cliff (2003 page 577) point out, individuals do not decide to start a business in a vacuum, they consult and are influenced by significant others in their environment. Perhaps it is time therefore that business advisers took more account of the influence of these significant others.

Finally, whilst it is important to acknowledge the importance of the family's influence on the business, the research also noted that the Vietnamese have a limited number of links to significant others outside their immediate network of family and friends. Even the second generation who were significantly better educated and had a wider network of contacts than their parents, tended to establish businesses in similar highly competitive business sectors where information and support from family and community networks was readily available. Thus communities such as the Vietnamese need to be encouraged to develop the skills, ideas, and support networks required 
to establish a more innovative range of businesses, which cannot be copied so easily by others. One possible source of new business opportunities and markets is the community's extensive global networks, and further research into how these operate, and how they could be developed to support business creation and expansion, would be useful. But further support programmes are needed which broker links between the community and a wider range of formal and informal networks able to provide business advice and the assistance required to turn new ideas into viable businesses.

Thus this paper has shown that business support for some of the smaller and more recently established BMEBs such as the Vietnamese needs to change if it is to facilitate the start-up and development of a more diverse range of successful businesses in inner city areas and in so doing contribute to social inclusion. In particular an enterprise support service is needed which seeks to understand the particular background, circumstances, significant networks, and cultural practices of each and every entrepreneur and which guards against stereotypical assumptions based on ethnicity, generation or age.

Acknowledgements. This research was funded by Business Link for London and the Nuffield Foundation. The author would also like to acknowledge the contribution of Khan M Nguyen, Nga Minh $\mathrm{Vu}$, Giang Nguyen, and Professor Michael Hitchcock who assisted with the programme of interviews.

\section{References}

Aldrich H E, Cliff J E, 2003 "The pervasive effects of family on entrepreneurship: toward a family embeddedness perspective" Journal of Business Venturing 18 573-596

Ajiferuke M, Boddewyn J, 1970, "'Culture' and other explanatory variables in comparative management studies' Academy of Management Journal 13 153-63

Bagwell S, Hitchcock M, K M Nguyen, 2003, Vietnamese Businesses in London Business Link for London, Centre Point, 103 New Oxford Street, WC1A 1DP

Baines S, Wheelock J, 1998, "Reinventing traditional solutions: Job creation, gender and the micro-business household" Work, Employment and Society 12 (4) 579-601

Basru A, 1998, "An exploration of entrepreneurial activity among Asian small businesses in Britain" Small Business Economics 10 313-326

Basru A, 2002, "The interaction between culture and entrepreneurship in London's immigrant businesses" International Small Business Journal 20 (4) 371-394

Basu A, 2004, "Entrepreneurial aspirations among family business owners: An analysis of ethnic business owners in the UK" International Journal of Entrepreneurial Behaviour and Research 10 (1/2) 12-33

Blackburn R, Rutherfoord R, 1999, Enterprise for Culturally Diverse Communities: A Survey of Ethnic Minority Business in the AZTEC Area, Small Business Research Centre, Kingston University, Kingston upon Thames, Surrey

Blackburn R, Stokes D, 2001, "Breaking down the barriers: Using focus groups to research small and medium-sized enterprises" International Small Business Journal 19 (1) 44-67

Cabinet Office Strategy Unit 2003 Ethnic Minorities and the Labour Market

Changanti R, Greene, P G, 2002, "Who are ethnic entrepreneurs? A study of entrepreneurs' ethnic involvement and business characteristics" Journal of Small Business Management 40(2) 126-143

Chan S, 1997, "Migration, cultural identity and assimilation effects on entrepreneurship for the overseas Chinese in Britain" Asia Pacific Business Review 3 211-222

Coleman J, 1988, "Social capital in the creation of human capital" American Journal of 
Sociology 94 595-620

Dhaliwal S, 1998, "Silent contributors- Asian female entrepreneurs and women in business" Women's Studies International Forum 21(5) 463-474

Dhaliwal S, 2003, "Perceptions of business support delivery to the UK minority ethnic business community." Paper presented at the $48^{\text {th }}$ International Council for Small Business Conference, Belfast 15-18 June.

Deakins D, 1996, Entrepreneurship and Small Firms $2^{\text {nd }}$ edition ( McGraw Hill, London)

Deakins, D, Ram M, Smallbone D, 2003 “Addressing the business support needs of ethnic minority firms in the United Kingdom" Environment and Planning C: Government and Policy 21 843-859

Dorais L J, 2001, "Defining the overseas Vietnamese" Diaspora 10 (1) 3-27

Duke K, Marshall T, 1995, Vietnamese Refugees since 1992, Home Office Research Study 142

Flap H, Kumcu A, Bulder B, 2000, 'Social capital and business success' in Rath, J. Immigrant Businesses: The Economic, Political and Social Environment Ed. J Rath (Macmillan Press, London) pp142-161

Fadahunsi A, Smallbone D, Supri S, 2000 "Networking and ethnic minority enterprise development: Insights from a North London study." Journal of Small Business and Enterprise Development 7 (3) 28-40

Financial World, 2003 "Ethnic Banking Minority Report" Financial World June 2003 36-40

GLE/CEEDR, 2000 Review of Business Support for Ethnic Minority Owned Businesses (EMBs) in London, Final Report, Greater London Enterprise, 28 Park Street, London SE1

Harris M, 1979 Cultural Materialism: The Struggle for a Science of Culture New York Random House

Hofstede G, 1980 Culture's Consequences: International Differences in Work-related Values Newbury Park A.A: Sage

Hofstede G, 1991 Cultures and Organisations: Software of the Mind. Cambridge M.A,University Press

Hofstede G, Bond M H,1988 "The Confucius connection: From cultural roots to economic growth" Organisational Dynamics 16, 4-21

Janjuha-Jivraj S, Woods A, 2002 "Successional issues within Asian family firms: Learning from the Kenyan experience". International Small Business Journal 20(1) 77-94 Sage

Johansson A W, 2004 "Narrating the entrepreneur" International Small Business Journal 22(3) 273-293 Sage

Kibria N,1994 "Household structure and family ideologies: The dynamics of immigrant economic adaptation among Vietnamese refugees" Social Problems 41(1) 81-96

Kloosterman R C, van der Leun J P, Rath J, 1999 "Mixed embeddedness, migrant entrepreneurship and informal economic activities" International Journal of Urban and Regional Research 23(2) 253-267

Lam T, Martin C, 1997, The Settlement of the Vietnamese in London: Official Policy and Refugee Responses, School of Education, Politics and Social Science, South Bank University, London

Lenartowicz T, Roth K, 1999 “A framework for culture assessment” Journal of International Business Studies 30 (4) 781-798

Light I H, P Bhachu (eds) 1993 Immigration and Entrepreneurship New Brunswick: Transactions Publishers

London Development Agency/Business Link for London 2004 London Annual Business Survey

London Development Agency 2005 Redefining London's BME-owned Businesses, London Development Agency

Marlow S, 1992, "Take-up of business growth training schemes by ethnic minority owned firms" International Small Business Journal 10 (4) 34-46

Masurel E, Nijkamp P, 2004, "Differences between first-generation and second-generation 
ethnic start-ups: implications for a new support policy" Environment and Planning C: Government and Policy 22 721-737

Metcalf H, Modood T,Virdee S, 1996 Asian Self-Employment: the Interaction of Culture and Economics in England, London, Policy Studies Institute.

Modood T, 1992 Not Easy Being British: Colour, Culture and Citizenship Runnymede Trust and Trendtham Books

Mulholland K, 1997, "The family enterprise and business strategies" Work, Employment and Society 11 (4) 685-711

Nieghbourhood Renewal Unit 2003 Research Report 5: Business-led Regeneration of Deprived Areas Neighbourhood Renewal Unit

Oc T, Tiesdell S, 1999, " Supporting ethnic minority business: A review of business support for ethnic minorities in City Challenge areas" Urban Studies 36 (10) 1723-1746

Pang M, 1999"The employment situation of young Chinese adults in the British labour market", Personnel Review 28 (1-2) 41-57.

Peters N, 2002, "Mixed embeddedness: Does it really explain immigrant enterprise in Western Australia (WA)?” International Journal of Entrepreneurial Behaviour \& Research, 8 (1/2) $32-53$

Poutziouris P, Yong, W, Chan S, 2002, "Chinese entrepreneurship: the development of small family firms in China" Journal of Small Business and Enterprise Development 9 (4) 383-399

Ralson D A, Egri C P, Stewart S, Terpstra R H, Kaicheng, Y, 1999a, “ Doing Business in the $21^{\text {st }}$ century with the new generation of Chinese managers: A study of generational shifts in work values in China" Journal of International Business Studies 30 (2) 415-428

Ralston D A, Thang NV, Napier N, 1999b, "A comparative study of the work values of North and South Vietnamese managers" Journal of International Business Studies 30 (4) 655-672

Ralston D A, Gustafson D J, Cheung F, Terpstra R H, 1993 "Differences in managerial values: A study of U.S. Hong Kong and PRC managers" Journal of International Business Studies 24(2) 249-75

Ram M,1997, "Ethnic minority enterprise: an overview and research agenda" International Journal of Entrepreneurial Behaviour and Research 3 (4) 149-156

Ram M, 1999 "Managing professional service firms in a multi-ethnic context: an ethnographic study" Ethnic and Racial Studies 22 (4) 697-701.

Ram M, Carter S, 2003, "Paving professional futures: Ethnic minority accountants in the United Kingdon" International Small Business Journal 21(1) 55-71

Ram M, Jones T, 1998 Ethnic Minorities in Business Small Business Research Trust

Ram M, Sanghera B, Abbas T, Barlow G, Jones T, 2000 "Ethnic minority business in comparative perspective: The case of the independent restaurant sector" Journal of Ethnic and Migration Studies 26 (3) 495-510

Ram M, Smallbone D, 2002, "Ethnic minority business policy in the era of the Small Business Service" Environment and Planning C: Government and Policy 20 235-249

Ram M, Smallbone D, 2003, "Policies to support ethnic minority enterprise: the English experience" Entrepreneurship \& Regional Development 15 151-166

Rosen S, Shenkar O, 1985 "Clustering countries on attitudinal dimensions: A review and synthesis" Academy of Management Review 10(3) 435-454

Saffu K, 2003, "The role and impact of culture on South Pacific island entrepreneurs" International Journal of Entrepreneurial Behaviour \& Research 9 (2) 55-73

Siu W, Zhu Y, Kirby D, 2003 "The interplay of environment and culture in small firm marketing: a comparative study of the marketing practices of Chinese small firms in Hong Kong and the UK" Journal of Small Business and Enterprise Development 10 (1) 25-39

Small Business Service 2004 A government action plan for small business. London, Small Business Service

Soar S, 1991 Business development strategies Paper presented at the TECs and ethnic minorities 
Conference, Warwick University

Smith E D , Pham C, 1996, "Doing business in Vietnam: A cultural guide" Business Horizons 39 (3) $47-51$

Tan J, 2002, "Culture, nation, and entrepreneurial strategic orientations: Implications for an emerging economy" Enterprise Theory and Practice 26 (4) 95-111

Thiessen J H, 1997, "Individualism, collectivism, and entrepreneurship: A framework for international comparative research" Journal of Business Venturing 12 367-384

Waldinger R, 1995, "The other side of embededdedness: a case study of the interplay of economy and ethnicity" Ethnic and Racial Studies 18 555-580

Ward R, 1984, "Minority settlement and the local economy" in Approaches to Economic Life: Economic Restructuring, Employment, and the Social Divisions of Labour Eds. Roberts B, Finnegan R, Gallie, D (Manchester: ESRC and Manchester University Press) pp198-212

Werber P, 1990, "Renewing an industrial past: British Pakistani entrepreneurship in Manchester" Migration 8 17-41

Yan J, Sorenson R L, 2004, “ The influence of Confucian ideology on conflict in Chinese family business" International Journal of Cross Cultural Management 4 (1) 5-17 